\title{
Campus Teaching Awards: 2018-2019 Academic Year
}

PSA is pleased to recognize the recipients of campus-wide and departmental awards for teaching excellence during the 2018-2019 academic year. Their contributions to teaching, mentorship, and future students create a lasting legacy in political science.

(Photos appear above recipient's name and institution). .

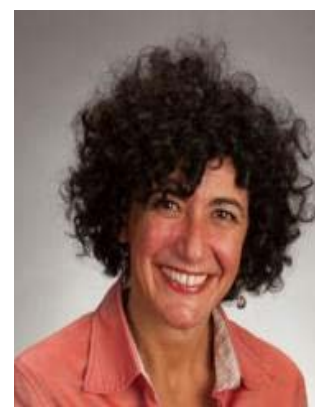

Rosa Aloisi, Trinity University Early Career Faculty Award for Distinguished Teaching and Research

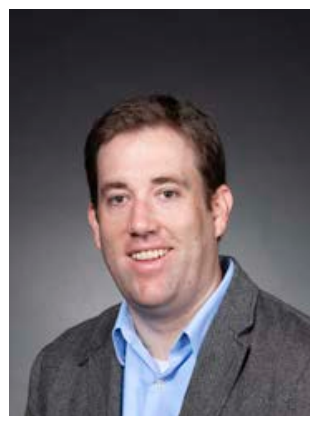

Kevin Evans, Florida International University

Faculty Award for Excellence in Teaching

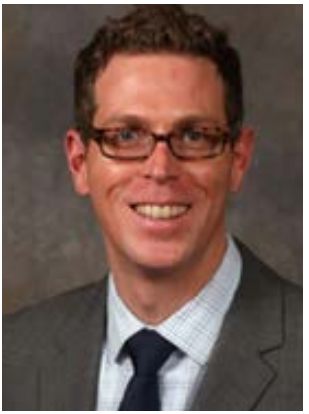

Paul Fritz, Hofstra University Distinguished Teacher of the Year

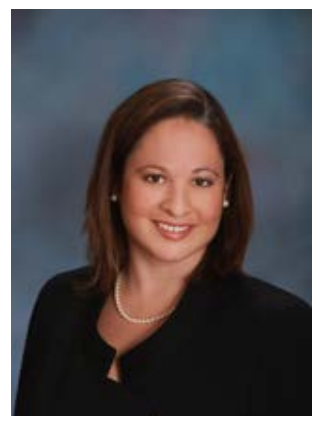

Lauren Bell, Randolph-Macon College Thomas Branch Award for Excellence in Teaching

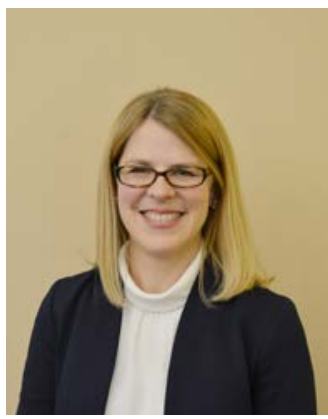

Erika Franklin Fowler, Wesleyan University

Binswanger Prize for Excellence in Teaching

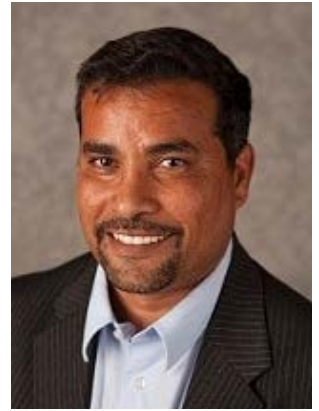

Gamal Gasim, Grand Valley State University

Grand Valley State University Senate Faculty Excellence Award

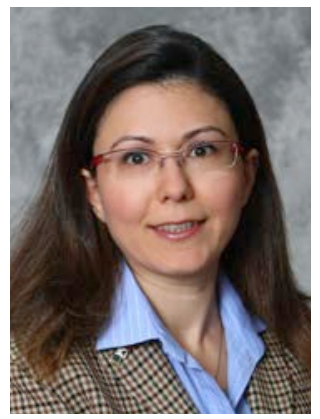

Evren Celik Wiltse, South Dakota State University

Honors College Teacher of the Year

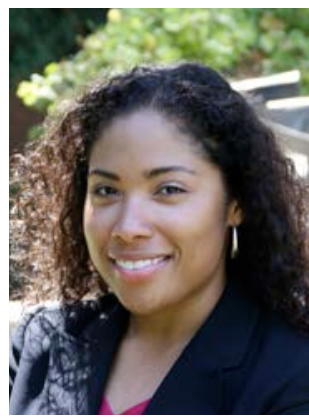

Lorrie Frasure-Yokley, University of California, Los Angeles Distinguished Teaching Award for Senate Faculty

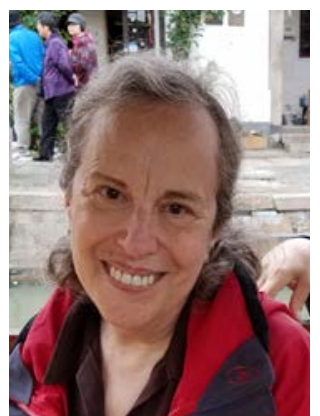

Marjorie Hershey, Indiana University Sylvia E. Bowman Award 


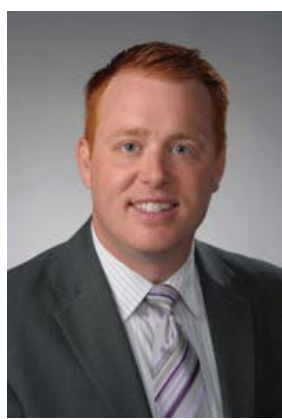

Seth Jolly, Syracuse University Excellence in Graduate Education Faculty Recognition Award

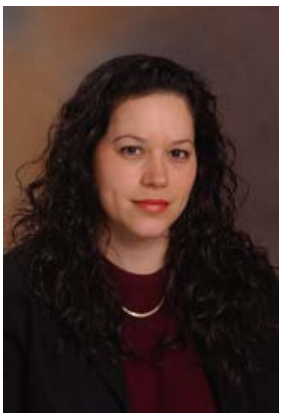

Alison Rios Millett McCartney,

Townson University

Campus Compact P2o Partnership Award

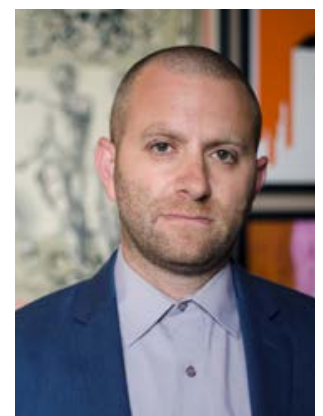

Joel Pruce, University of Dayton Faculty Award for Outstanding Teaching in the College of Arts and Sciences

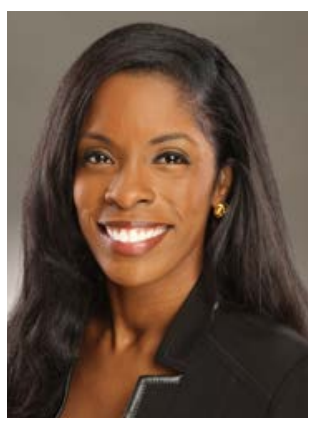

Deondra Rose, Duke University The Susan Tifft Undergraduate Teaching and Mentoring Award

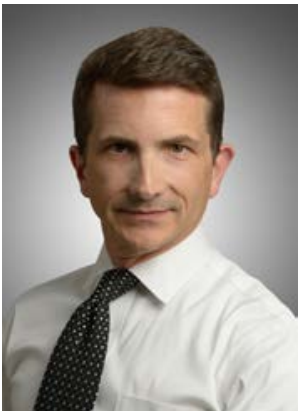

Drew Lanier, University of Central Florida College of Sciences Undergraduae Teaching Excellence Award

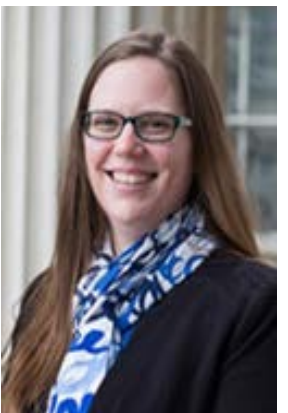

Elizabeth Menninga, University of Iowa Collegiate Teaching Award

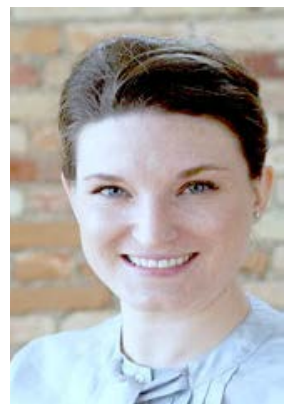

Katherine Robiadek, University of

Wisconsin, Madison

Distinguished Fellow Award from the UW Madison Teaching Academy

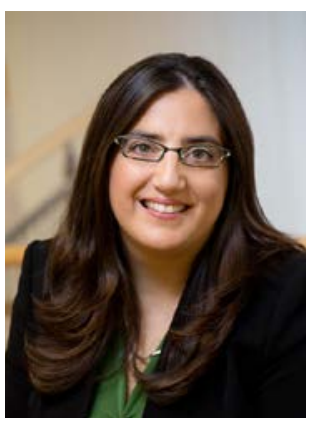

Gisela Sin, University of Illinois Dean's Award for Excellence in Undergraduate Teaching

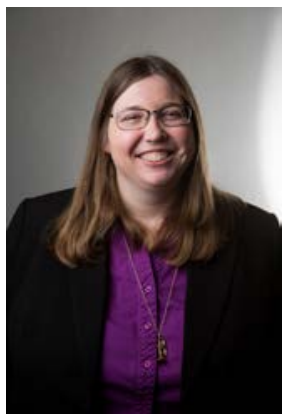

Debra Leiter,

University of Missouri, Kansas City

UMKC College of Arts and Sciences Alumni Outstanding Teaching Award

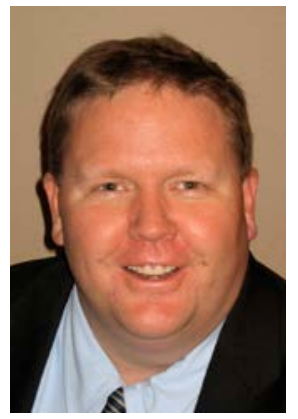

Jeremy Pope, Brigham Young University General Education Professorship

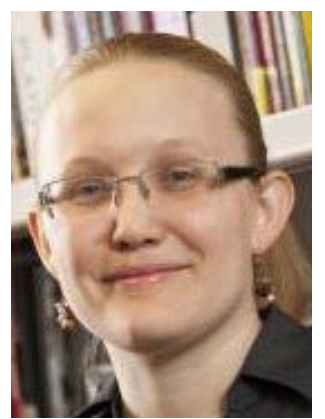

Laura Roost, Newberry College Omega Psi Phi Fraternity, Alpha Delta Chi Chapter Teacher Appreciation Award

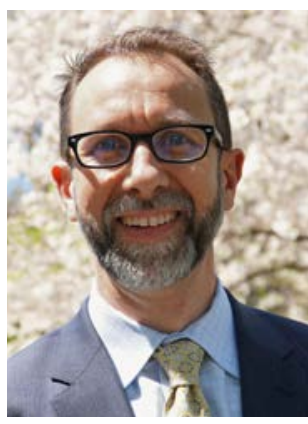

Randall Smith, Franklin College Faculty Teaching Excellence Award 


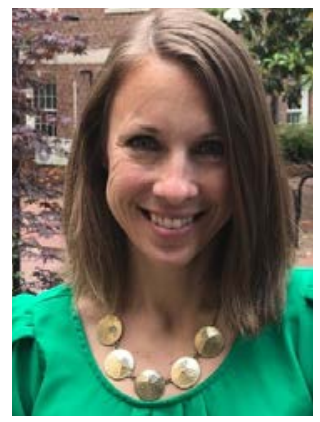

Sarah Treul, University of North Carolina, Chapel Hill

Bowman and Gray Term Professorship, The Chapman Family Teaching Award, The Honors Carolina Manekin Award for Teaching Excellence

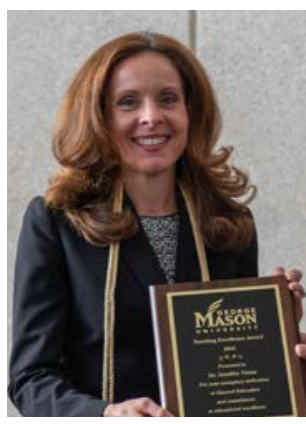

Jennifer Victor, George Mason University George Mason University Teaching Excellence Award

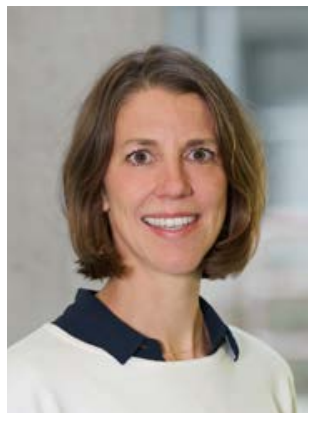

Christina Zuber, University of Konstanz University of Konstanz Award for Teaching Excellence 